\title{
More Depressive: More Hostile. Less Depressive: Not, Necessarily, Less Hostile...
}

\author{
Balta GT, Angelopoulos NV
}

\begin{abstract}
Background. Purpose of this study was the investigation of the relationships between depressive symptoms and features of hostility in psychiatric patients with the passage of time.

Methods. In two groups of psychiatric patients (DI and DII) two successive measurements, with a time interval of 4-6 weeks, were carried out with the Hostility and Direction of Hostility Questionnaire (HDHQ) and the state of Depression (SD) subscale of the Delusions Symptoms States Inventory (DSSI). The DI group $(\mathrm{N}=39)$ consisted of patients who reported lower scores on the (sD) subscale at the second measurement. The DII group $(\mathrm{N}=20)$ consisted of patients who reported higher scores on the ( $\mathrm{sD})$ subscale at the second measurement.

Results. In the DI group, the significant decrease of $\mathrm{SD}$ scores was accompanied by an analogously significant drop of the scores of all HDHQ subscales. In the DII group the significant increase of the SD scores was not followed by significant increase of hostility levels, with the exception of Criticism of Others and Paranoid Hostility. In the subscale of Guilt the scores actually were dropped, though non-significantly.

Conclusions. These findings may suggest that although depressive symptoms are related to certain hostility factors, this relationship is not stable but changes according to the course of depression, in the sense that it is strong when depression decreases, but not so significant when depression increases.

Index Terms: Depression, Hostility.
\end{abstract}

\section{INTRODUCTION.}

The relationship between affective symptoms and hostility has had been a matter of research and discussion since the emergence of psychoanalysis, and depression was the target of this research because of its great clinical interest and availability. Inwardly directed hostility has been considered as a fundamental ingredient in the formation process of depressive symptoms. Since the first psychoanalysts (Abraham, 1911; Freud, 1917) it has been postulated that melancholia stemmed from the actual or symbolic threatened loss of a loved object and the hostility - originally felt against it was turned against the self, through the mechanism of introjection. This theoretical view, however, has not been convincingly supported by empirical evidence since numerous clinical observations have indicated that depression is not associated only with the characteristic attitudes of introverted hostility such as feelings of guilt, self-blame and worthlessness.

Balta GT, M.D, Ph. D, University of Thessaly, Medical School, Department of Psychiatry, Biopolis, Larissa, Greece

Angelopoulos NV, Professor of Psychiatry, University of Thessaly, Medical School, Department of Psychiatry, Biopolis, Larissa, Greece
It is, also, frequently accompanied by features of outwardly directed hostility, such as anger, resentment, irritability and demanding behavior. If hostility is considered to have any significant role at all in depression, it would be reasonable to expect change in its status and expression, as depressive between symptoms ameliorate.

It has been proposed that depression is associated with introverted hostility (Foulds, 1965; Caine et al, 1967) and that the more severe the depression is, the more the hostility is directed inwardly (Mayo, 1970; Freedman, 1970). As depression improves there is a reduction of general and especially introverted hostility (Foulds, 1965; Philip, 1971; Blackburn, 1974; Fernardo, 1977; Lyketsos et al, 1978). Moreno et al (1994) observed significant positive correlations between self-reported severity of depression and all subtypes of hostility, but the Intropunitive scale of the HDHQ was the single most powerful predictor of depression. Foulds and Caine (1959) found that a self-criticism personality scale behaved very much the same way as a depression scale, and Vinoda (1966) observed in attempted suicide patients that scores on intropunitiveness were higher than those of psychiatric controls. It was also reported (Gottschalk et al 1963) that "hostility in" was correlated positively with the degree of depression, whereas the correlation between "hostility out" and depression was close to zero. On the other hand extraverted hostility has been reported that increases with improvement of depression (Salmon, 1964; Foulds, 1965; Philip, 1971). Another epidemiological point of view, supports the hypothesis that depression is caused by the frustration of aggressive responses. Evidence was provided (Kendel 1970) that there tends to be an inverse relationship between suicide and homicide, that subcultures discouraging outward expressions of hostility have a higher depression rate, that women are less aggressive and more prone to depression than men and older men more so than younger men and that rates of depression and suicide are lower during wars (Lyons, 1972).

The alternative notion that hostility in depression does not necessarily take a predominantly intropunitive direction and that hostility-out and depression coexist and are not negatively correlated has also been supported. Wessman et al (1960) found that the frequency of extrapunitive responses was higher in depressed females whereas the frequency of intropunitive responses was not increased significantly. Schless et all (1974) observed that half of their depressed patients showed a predominance of outward hostility and the other half of inward hostility. Lazare and Klerman (1968) found that in women with hysterical personalities hostilityout increased with deepening depression and subsided with 
improvement. Weissman et al (1971) suggested that patients with "hostility-out" are less depressed than the classic patients with "hostility-in". Intercorrelations among hostility, anger, and depression scales offer some support for the hypothesis that depression is linked most strongly with attitudinal versus motoric forms of hostility (Moreno et al 1993).

Researchers have shown interest in the relationship between depression and hostility. Aikens and Klinkman in 2012 investigated changes in patients' beliefs about their antidepressant during the acute phase of depression treatment (Aikens et Klinkman, 2012). Van Montfort E et al, in 2017, among a population of 681 coronary artery disease patients, have found negative affectivity to be associated with high hostility (van Montfort E et al, 2017). Parker et Roy, through a review in 2001, came to the conclusion that, for the majority who develop adolescent depression, its expression and outcome appear more a reflection of the propagating determinants, most commonly anxiety and personality style, like hostility (Parker et Roy, 2001). Parker et Graham in 2015, while examining patients with 'irritable', 'hostile' and 'anxious' depression, suggested that hostile and irritable depression are synonymous patterns (Parker et Graham, 2015).

Our goal was to shed light into the changes occurring in psychology features, when depressive symptoms alleviate. So, the present study's purpose was to investigate the patterns of hostility during recovery or deterioration of depressive symptoms in psychiatric patients, regardless their psychiatric diagnosis.

\section{METHODS}

The self-report questionnaires known as Delusions Symptoms States Inventory (DSSI) and Hostility and Direction of Hostility Questionnaire (HDHQ), were given to 132 patients, presenting a wide range of psychiatric disorders, consecutively admitted to the Department of Psychiatry, St Mary's Hospital, London. Criteria for inclusion to the study were, age between 17 and 65 years and ability to cooperate to the testing procedure. The patients completed the first battery of questionnaires within seven days of their admission and a second battery was administered after an interval of approximately 4-6 weeks.

Sixty-four patients scored above the cut-off on the state of Depression (sD) scale in the first measurement. From those, on the second measurement, 39 gave a score lower than that given in the first and 20 scored higher. In five patients, both scores were equal and they were not included in the study. Thus, two groups were formed for the study: In the first group (DI), belong those who reported lower scores on the sD scale at the second measurement and could be considered as improved from their depressive symptoms. The participants of this group were 39 (15 males and $24 \mathrm{fe}-$ males) with a mean age 36.6. In the second group (DII), belong those who reported higher scores on the $\mathrm{sD}$ scale at the second measurement and have been regarded that their depressive symptoms were deteriorated. The participants of this group were 20 (9 males and 11 females) with a mean age 33.9 .

The HDHQ (Caine et al., 1967) was devised as an attitudinal measure for a wide range of possible manifestations of hostility, having little implication of aggressive behaviour physically expressed. Two broad dimensions underlie hostility as it is measured by the HDHQ: a readiness to respond with aggressive behaviour and a tendency to evaluate persons, including the self, in negative and unfavourable terms. It consists of five subscales in 51 items. Three subscales, Acting-Out Hostility, Criticism of Others and Paranoid Hostility are measures of Extrapunitiveness or Extraverted Hostility. Acting-Out Hostility consists of items implying a readiness to manifest a physical aggressive behaviour. Criticism of Others consists of items implying negative evaluations about persons other than the self. Paranoid Hostility implies a feeling of direct personal receipt of hostility, a belief in an act of open enmity. Two subscales, Guilt and Self-Criticism are measures of Intropunitiveness or Introverted Hostility. Guilt represents feelings of guilt and low self-esteem. SelfCriticism represents a tendency to belittle one's own achievements. Total Hostility is the sum of the five subscales. The Direction of hostility (Di) score indicates a balance between Introverted and Extraverted hostility and is obtained by the formula: $(\mathrm{AH}+\mathrm{CO}+\mathrm{PH})-(2 \mathrm{SC}+\mathrm{G})$. Positive $\mathrm{Di}$ scores indicate predominance of intropunitiveness whilst negative scores indicate predominance of extrapunitiveness. Generally, the accepted norms for total hostility in normal populations are between 12-14 (Caine et al. 1967) but higher norms have also been suggested (McPherson, 1988). The HDHQ has been used in normal Greek populations (Economou and Angelopoulos, 1989) and patients suffering from psychiatric (Lyketsos et al, 1978) or somatic illnesses (Angelopoulos et al 1995; Angelopoulos et al 1996).

The DSSI (Foulds and Bedford, 1975; Bedford and Foulds, 1978) consists of 84 items in twelve sets, allocated in four Classes: Class I, named Dysthymic States, includes state of Anxiety, state of Depression and state of Elation. Class II, named Neurotic Symptoms, includes Conversion symptoms, Dissociative symptoms, Phobic symptoms, Compulsive symptoms and Ruminative symptoms. Class III, named Integrated Delusions, includes Delusions of Persecution, Delusions of Grandeur and Delusions of Contrition. Class IV includes Delusions of Disintegration. Each item is scored $0,1,2$, and 3 according to the degree of distress or, in the case of delusions, upon the certainty of the belief. A score of four or more on any set of items is the criterion for membership of that set and the class of which it is a constituent. The state of depression (sD) subscale, which is considered for the present study, consists of seven items each measuring symptoms of non-psychotic depression. The total score is the sum of the scores of its items (range 0-21) and the cut off score is 3 (Foulds 1976). This is not a well-known or widely used instrument despite its interesting properties, which make it preferable in screening studies. It is very easy to complete and gives a simple and rapid evaluation of de- 
pression. It focuses exclusively on recent symptoms, uncontaminated by items related to personality or other attributes. In Greek populations data from normals as welll as psychiatric and medical patients are available (Angelopoulos and Economou, 1994; Angelopoulos et al 1995; Angelopoulos et al 1996).

The statistical analysis was carried out by using the Statistical Package for the Social Sciences, SPSS (Norusis, 1992). Since all the examined variables were ordinal the nonparametric rank-order correlation coefficient Kendall's $\tau$ b (Kendall, 1962) was used. The case for using this coefficient with psychometric data has been argued by Priest (1976). Briefly, Kendall's $\tau$-b, is a coefficient of association that makes no assumptions about the normality of the underlying distribution of the data (other than that can be seen as categories ranked in order), it is appropriate for the ordinal level of measurement (e.g. rank on one to three on a rating scale) it does not give undue value to outlying scores, gives coefficients of rank ordered correlations and a level of statistical significance and allows a partial correlation coefficient to be calculated if necessary.

\section{RESULTS}

Table 1 presents the diagnoses given to the participated patiends of groups DI and DII during their hospitalization. There is a rather broad spectroum of psychiatric diagnoses in groups DI and DII suggesting that depressive symptoms in their relationship to hostility were examined regardless of each patient's diagnosis.

Table 2 presents the scores obtained on HDHQ and the sD subscale of DSSI from the patients of group DI in the two measurements. Very high scores on hostility were reported in the first and second measurement. The Total Hostility mean score, for example, was almost double than that proposed as a norm by Caine et al (1967). Direction of hostility scores were highly positive indicating a hostility balance towards intropunitiveness. There was a highly statistically significant drop of sD scores and similarly significant decreases of the hostility subscales, with the exception of Criticism of Others subscale which showed a less significant decrease. Total Intropunitiveness was dropped more significantly than Total Extrapunitiveness.

Table 3 presents the scores obtained on HDHQ and the sD subscale of DSSI from the patients of group DII in the two measurements. Very high scores on hostility were reported in the first and the second measurement from the patients of this group. Also in thi group direction of hostility scores were highly positive suggesting a hostility balance towards intropunitiveness. Although the increase of the sD scores was highly significant in this group, from the HDHQ subscales only Criticism of Others and Paranoid hostility, to a lesser degree, increased significantly. Surprisingly, Guilt did not follow the increase of $\mathrm{sD}$ scores and showed a, though non-significant, decrease of mean scores. Total extrapunitiveness and total intropunitiveness were increased marginaly significantly.

\section{DISCUSSION}

The heterogeneity of the diagnostic categories of the participants could be regarded as a limitation of the study, since the depressive symptoms were examined regardless of each patients' diagnosis. Nevertheless, the purpose of this procedure was the development of depressive symptoms and mode of hostility, regardless each specific diagnosis, and this is the proposed viewpoint in the present study.

The notion supporting a positive relationship between depression and extraverted hostility could be regarded as being in accordance with the findings of the present study. An inverse relationship between those features was not observed in both groups and the view that the amelioration of depression is associated with an increasing expression of hostility does not seem to get decisive support. The levels of extraverted hostility were increased in both DI and DII group. However, it should be stated that intropunitiveness had a closer affinity than extrapunitiveness to the $\mathrm{SD}$ scores in the DI group, whereas extrapunitiveness was more related to $\mathrm{sD}$ scores than intropunitiveness in the DII group.

The close relationship observed between depressive symptoms and the two intropunitive subscales of Guilt and Self-Criticism in the DI group only, suggests that these hostility features cannot be regarded as behaving as diagnostic measures for depression (Adams and Foulds, 1962; 1963). This could happen if, during the course of symptomatology, Guilt and Self-Criticism were parallel not only on the decrease but also on the increase of the $\mathrm{SD}$ scores

The association of $\mathrm{sD}$ with Acting Out Hostility ( $\mathrm{AH})$ is very close in the 'improved' group but not in the 'deteriorated'. This is interesting from a clinical point of view. Acting Out hostility could be regarded as the way through suicidal ideas may be realized. It could be then hypothesized that since $\mathrm{AH}$ does not follow depression as it increases, this seems to be a protective mechanism functioning as an inhibiting factor to the actualization of suicidal thoughts.

Perhaps the most interesting finding of the present study is the mode of association between sD and Criticism of Others. On remission of depressive symptoms there is not a substantial drop of Criticism of Others contrary to the other hostility subscales, whereas on deterioration there is a highly significant increase of Criticism of Others. The depressed patient does not stop to evaluate negatively people and situations even when he/she becomes less depressed. When depressive symptoms decrease, $\mathrm{CO}$ remains almost unchanged, suggesting that the nature of this hostility variable is closer to personality than to psychopathology. More generally it could be proposed that in the present study appears the wellknown phenomenon (Foulds, 1976) of the stability of hostility features, and the changeability of depressive symptomatology.

\section{CONCLUSIONS}

Hostility features so sensitive to the course of depressive symptoms as to be indicators of its severity, were not de- 
tected in the present study, not even guilt. Depressive symptoms do have parallel courses with certain hostility features but this happens up to a degree and according to the depressive symptoms course. Depressive symptoms, when deteriorating, could be 'disconnected' from hostility and they are not followed by analogous changes from hostility. This phenomenon reflects the resistance and inelasticity of the personality to change and the plasticity of the psychiatric symptoms. The classical view that the depressed patient expresses only features of introverted hostility seems to be rather simplistic. The findings of the present study suggest that instead to the formulation implying a negative relationship between extrapunitiveness and depression there could be alternative patterns in which exteriorized hostility and depression coexist and in which the respective changes are not negatively correlated.

Acknowledgements. Many thanks to Dr Raptopoulos P., and Professor Priest, P.G. for their valuable assistance.

\section{REFERENCES}

Abraham, K., (1911). Notes on the psychoanalytical investigation and treatment of Manic-Depressive insanity and allied conditions. In Selected papers on Psychoanalysis. London, Hogarth Press, 1949.

Adams, A., Foulds, G.A., (1962). Depression and Personality. J. Ment. Sci. 108:474-76.

Adams, A., Foulds, G.A., (1963). Personality and Paranoid Depressive Psychoses. Brit. J. Psychiat. 109, 273-278.

Aikens, J.E., Klinkman, M.S., (20120. Changes in patients' beliefs about their antidepressant during the acute phase of depression treatment. Gen Hosp Psychiatry. 2012 May-Jun;34(3):221-6.

Angelopoulos, N.V., Economou, M., (1994). Prevalence of Dysthymic states in a group of High School Students. Europ. Psychiatry 9, 19-26.

Angelopoulos, N.V., Tzivaridou, D., Nikolaou, N., Pavlidis, N., (1995). Psychiatric Symptoms, hostility features and stressful life events in patients with cancer. Acta Psychiat. Scand. 92, 44-50.

Angelopoulos, N.V., Mantas, C., Massalas, K., Vasalos, K., Tsianos, E., (1996). Psychiatric symptoms hostility and life events in ulcerative colitis patients during active phase and remission. Europ. J. Psychiat. 10:2, 87-99.

Bedford, A., Foulds, G.A., (1977). Validation of the Delusions Symptoms States Inventory. Brit. J. Med. Psychol. 50, 163-171.

Bedford, A., Foulds, G.A., (1978). Delusions Symptoms States Inventory. (Manual). NFER Publishing Co. Windsor.

Blackburn, I., (1974). The pattern of hostility in affective illness. Brit. J. Psychiat. 125,141-5.

Caine, T.M., Foulds G.A., Hope K., 1967. Manual of the Hostility and Direction of Hostility Questionnaire. London, University of London Press.

Economou M., Angelopoulos N.V., (1989). Dysthymic Symptoms, Hostility and Scholastic Achievement in a Group of High School Students. Educ. Psychol., 9:4, 331-337.

Fernardo, S.M., (1977). Hostility, Personality and Depression. Brit. J. Med. Psychol. 50, 243-49.

Foulds, G.A., (1965). Personality and Personal illness. Tavistock. London. Foulds, G.A., (1976). The Hierarchical Nature of Mental Illness. Acad. Press, London.
Foulds, G.A., Bedford, A., (1976). Euphoria, Elation and Impunitiveness. J. Clin. Psychol. 32, 606-09.

Foulds, G.A., Caine, T.M., Creasy, M.A., (1960). Aspects of extra- and intro-punitive expression in mental illness. J. Ment. Sci. 105:599-610.

Foulds, G.A., Caine, T.M., (1959). The assessment of some symptoms and signs of depression in women. J. Ment. Sci., 105:182-189.

Freud, S., (1917). Mourning and Melancholia. Standard Edition vol. 14, London, Hogarth Press, 1957.

Friedman, A.S., (1970). Hostility factors and clinical improvement in depressed women. Arch. Gen. Psychiat. 23, 524-537.

Gottschalk, L.A., Glesser, G.C., Springer, K.J., (1963). Three hostility scales applicable to verbal samples. Arch Gen. Psychiat. 9, 254-279.

Kendall, M.G., (1962). Rank Correlation Methods. Griffin, London.

Kendell, R.E., (1970). Relationship between aggression and depression. Epidemiological implications of a hypothesis. Arch. Gen. Psychiat. 22, 308318.

Lazare, A., Klerman, G.L., (1968). Hysteria and depression. The frequency and significance of hysterical personality. Features in hospitalised depressed women. Am. J. Psychiat. 124:48-56.

Lyons, H.A. (1972). Depressive illness and aggression in Belfast. Brit. Med. J. 1:342-4.

Lyketsos, G.S., Blackburn, I.M., Tsiantis, J., (1978). The movement of hostility during recovery from depression. Psychol. Med. 8, 145-149.

Mayo, P.R., (1967). Psychological changes associated with improvement of depression. Brit. J. Soc. Clin. Psychol. 6, 63-68.

McPherson, F.M., (1988). A note on the female norms of the HDHQ. Brit. J. Clin. Psychol. 27, 263-264.

Moreno, J.K., Selby, M.J., Fuhriman, A., Laver, G.D., (1994). Hostility in Depression. Psychol Rep. 75:3Pt1, 1391-1401.

Moreno, J.K., Fuhriman, A., Selby, M.J., (1993). Measurement of hostility, anger, and depression in depressed and nondepressed subjects. J. Pers. Assess. 61:3, 511-523.

Norusis, M., (1992). SPSS for Windows: Base System Users Guide, Release 5.0 SPSS Inc. Chicago, Ill.

Parker, G., Graham, R., (2015). Anxious, irritable and hostile depression reappraised. J Affect Disord. 2015 Aug 15; 182:91-4.

Parker, G., Roy, K., (2001). Adolescent depression: a review. Aust N Z J Psychiatry. Oct;35(5):572-80.

Philip, A.E., (1971). Psychometric changes associated with response to drug treatment. Brit. J. Soc. Clin. Psychol. 10, 138-143.

Priest, R.G., (1976). The homeless person and the psychiatric services: An Edinburgh survey. Brit. J. Psychiat. 128, 128-136.

Salmon, P., (1964). Foulds' punitiveness scales in relation to MMPI. Validation and diagnostic scales. Brit. J. Soc. Clin. Psychol. 4, 207-213.

Schless, A.P., Mendels, J., Kipperman, A., Cochrane, C., (1974). Depression and hostility. J. Nerv. Ment. Sci. 159, 91-100.

van Montfort, E., Denollet, J., Vermunt, J.K., Widdershoven, J., Kupper, N., (2017). The tense, the hostile and the distressed: multidimensional psychosocial risk profiles based on the ESC interview in coronary artery disease patients - the THORESCI study. Gen Hosp Psychiatry Jul; 47:103-111. Vinoda, K.S., (1966). Personality characteristics of attempted suicide. Brit. J. Psychiat. 112, 1143-1150.

Weissman, N.M., Klerman, G.L., Paykel, E.S., (1971). Clinical evaluation of hostility in depression. Am. J. Psychiat. 128, 261-266.

Wessman, A.E., Ricks, D.E., Tyl, M.M., (1960). Characteristics and concomitants of mood fluctuation in college women. J. Abnorm. Soc. Psychol. 60:117-126. 
Table 1. Diagnoses given to the participated patients.

\begin{tabular}{|l|l|l|}
\hline Diagnosis & Group DI & Group DII \\
\hline Neurotic Depression & 16 & 9 \\
\hline Anxiety state & 1 & 1 \\
\hline Personality Disorder & 4 & - \\
\hline Anorexia Nervosa & 1 & - \\
\hline Schizophrenia & 11 & 8 \\
\hline Schizo-affective Disorder & 1 & 1 \\
\hline Bipolar Illness (Depression) & 3 & - \\
\hline Bipolar Illness (Mania) & 1 & - \\
\hline Psychotic Depression & 1 & 1 \\
\hline TOTAL & 39 & 20 \\
\hline
\end{tabular}

Table 2. Group DI (decreased depression, N=39). Descriptive statistics and Kendall's $\tau$-b correlation coefficients.

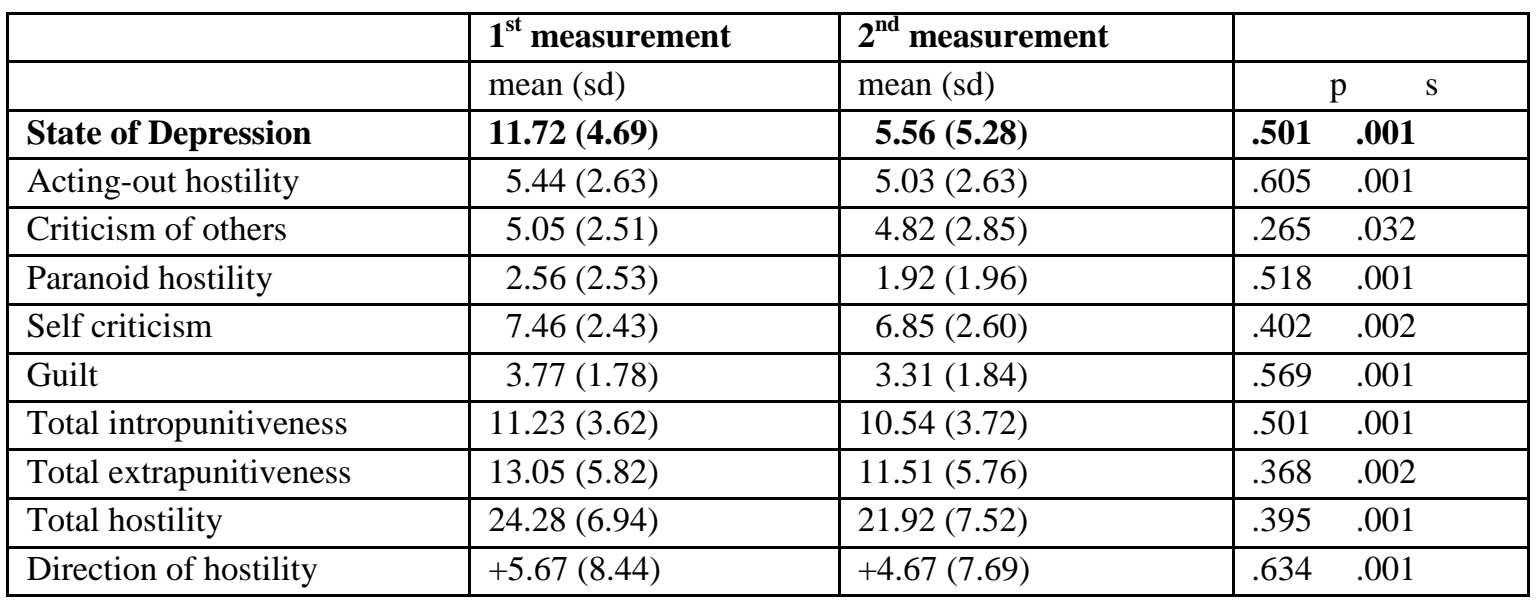

Table 3. Group DII (deteriorated depression, $N=20$ ). Descriptive statistics and Kendall's $\tau$-b correlation coefficients.

\begin{tabular}{|l|l|l|ll|}
\hline & $\mathbf{1}^{\text {st }}$ measurement & $\mathbf{2}^{\text {nd }}$ measurement & \\
\hline & mean $(\mathrm{sd})$ & mean $(\mathrm{sd})$ & $\mathrm{p}$ & $\mathrm{s}$ \\
\hline State of depression & $\mathbf{8 . 0 5}(\mathbf{5 . 2 7})$ & $\mathbf{1 1 . 9 5}(\mathbf{4 . 7 5})$ & $\mathbf{. 6 8 2}$ & $\mathbf{. 0 0 1}$ \\
\hline Acting-out hostility & $5.15(2.45)$ & $6.50(2.56)$ & .152 & .391 \\
\hline Criticism of others & $5.15(2.39)$ & $5.25(2.65)$ & .566 & .002 \\
\hline Paranoid hostility & $2.70(2.08)$ & $2.90(2.67)$ & .450 & .014 \\
\hline Self criticism & $6.90(2.15)$ & $7.60(2.60)$ & .313 & .084 \\
\hline Guilt & $4.05(2.11)$ & $3.65(2.06)$ & .206 & .258 \\
\hline Total intropunitiveness & $10.95(3.68)$ & $11.25(4.91)$ & .383 & .028 \\
\hline Total extrapunitiveness & $13.00(4.63)$ & $14.65(5.87)$ & .387 & .023 \\
\hline Total hostility & $23.95(7.44)$ & $25.90(7.93)$ & .399 & .019 \\
\hline Direction of hostility & $+4.20(4.26)$ & $+3.70(7.67)$ & .310 & .068 \\
\hline
\end{tabular}

